\title{
Apparent oxygen utilization rates calculated from tritium and helium-3 profiles at the Bermuda Atlantic Time-series Study site
}

\author{
R. H. R. Stanley, S. C. Doney, W. J. Jenkins, and D. E. Lott, III \\ Marine Chemistry and Geochemistry Department, Woods Hole Oceanographic Institution, Woods Hole MA 02543 USA \\ Correspondence to: R. H. R. Stanley (rstanley@whoi.edu)
}

Received: 14 September 2011 - Published in Biogeosciences Discuss.: 11 October 2011

Revised: 2 April 2012 - Accepted: 5 April 2012 - Published: 4 June 2012

\begin{abstract}
We present three years of Apparent Oxygen Utilization Rates (AOUR) estimated from oxygen and tracer data collected over the ocean thermocline at monthly resolution between 2003 and 2006 at the Bermuda Atlantic Timeseries Study (BATS) site. We estimate water ages by calculating a transit time distribution from tritium and helium-3 data. The vertically integrated AOUR over the upper $500 \mathrm{~m}$, which is a regional estimate of export, during the three years is $3.1 \pm 0.5 \mathrm{~mol} \mathrm{O}_{2} \mathrm{~m}^{-2} \mathrm{yr}^{-1}$. This is comparable to previous AOUR-based estimates of export production at the BATS site but is several times larger than export estimates derived from sediment traps or ${ }^{234} \mathrm{Th}$ fluxes. We compare AOUR determined in this study to AOUR measured in the 1980s and show AOUR is significantly greater today than decades earlier because of changes in AOU, rather than changes in ventilation rates. The changes in AOU are likely a methodological artefact associated with problems with early oxygen measurements.
\end{abstract}

\section{Introduction}

Recently, a number of papers have been published in the scientific literature suggesting that the oxygen content in the ocean is decreasing (Keeling et al., 2010; Stramma et al., 2008, 2010; Whitney et al., 2007). This decrease, both predicted in models (Bopp et al., 2002; Matear and Hirst, 2003; Plattner et al., 2001) and seen in data (Stramma et al., 2008, 2010; Whitney et al., 2007), is due to the ocean becoming warmer and more stratified. The decrease in oxygen is not necessarily monotonic and can be affected by modes of climate variability (Deutsch et al., 2011). Deoxygenation is likely to affect the elemental cycles of many biogeochem- ically relevant species (C, N, P, Fe) (Codispoti et al., 2001; Wallmann, 2003). Additionally, most organisms are sensitive to oxygen levels, with a nonlinear sensitivity at low oxygen levels, suggesting that large-scale negative ecosystem consequences to deoxygenation may occur (Vaquer-Sunyer and Duarte, 2008). Documenting and understanding the nature of the trend in oceanic oxygen is important both from the viewpoint of global environmental change as well as for furthering our knowledge of the biogeochemical cycling of carbon and other elements. Time-series data of oxygen records are vital for addressing this question. Futhermore, diagnosing the magnitude of oxygen sinks within the water column is key to developing our understanding of the relevant biogeochemical dynamics.

One method for quantifying the biological oxygen sinks is to determine Apparent Oxygen Utilization Rates (AOUR), a geochemical tracer-based metric of export production which integrates over a large geographic area. AOUR are calculated by combining oxygen utilization data with a natural "clock", typically a tracer that yields information on the age of the water mass. Geochemical clocks for dating water include tritium/helium-3 (T/3 He) (e.g. Jenkins, 1977, 1980, 1988, 1998), chlorofluorocarbons (CFC) (e.g. Doney and Bullister, 1992; Smethie and Fine, 2001), and for the upper few hundred meters ${ }^{7} \mathrm{Be}$ (Kadko, 2009). Tritium decays with a 12.31 year half-life to ${ }^{3} \mathrm{He}$, a stable, inert isotope (MacMahon, 2006). The primary source of tritium to the contemporary ocean is from tritium released by the atmospheric thermonuclear bomb tests in the $1960 \mathrm{~s}$. Thus, $\mathrm{T} /{ }^{\beta} \mathrm{He}$ is most useful for dating water that has been at the surface within the last 50 years. When the water is at the surface, excess ${ }^{3} \mathrm{He}$, i.e. ${ }^{3} \mathrm{He}$ concentration above the solubility value, is almost completely lost due to gas exchange. As water is sequestered 
from the atmosphere and ages, excess ${ }^{3} \mathrm{He}$ builds up and tritium decreases. In theory, the radioactive decay equation could be used to estimate ventilation ages. In practice, however, mixing complicates matters and thus simple box models have been used in order to estimate ventilation time scales (Doney and Jenkins, 1988; Jenkins, 1980). Here we apply both the box model approach and a newer, more sophisticated approach, namely using Transit Time Distributions (TTD) (Waugh et al., 2003) to calculate ventilation ages.

The apparent oxygen utilization (AOU) - the difference between equilibrium $\mathrm{O}_{2}$ and measured $\mathrm{O}_{2}$ - results from $\mathrm{O}_{2}$ being consumed during respiration of exported organic matter in the water column. By combining the ventilation age of the water in the aphotic zone with the AOU, we can calculate the apparent oxygen utilization rate (AOUR). The vertical integral of AOUR is often taken as a measure of export production from the euphotic zone. However, the AOUR of a water parcel represents the time averaged oxygen consumption rate along an isopycnal path from when the water was first subducted to when it arrived at a given site. Thus, the depth-integrated AOUR is not simply a measure of local export but rather is a projection of geographic and horizontally distributed processes working on individual isopycnal layers and hence represents a regional view of export flux. This key point is discussed in more detail in Sect. 4.1.

In this paper, we present AOUR as determined from $\mathrm{T}$ and ${ }^{3} \mathrm{He}$ ages, calculated using transit time distributions, at the Bermuda Atlantic Time-series Study (BATS) site, a typical subtropical oligotrophic gyre location. BATS is an ideal location for this work as there is a wealth of geochemical data for comparison. A time-series of many biogeochemical parameters has been measured at BATS since 1988 (Michaels and Knap, 1996; Steinberg et al., 2001). Tritium and ${ }^{3} \mathrm{He}$ have been measured at BATS and nearby Station S at various times since the mid-1970s (Jenkins, 1977, 1998, 1980, 1988). Export production has been calculated at BATS, specifically, and in the Sargasso Sea in general, from the AOUR method (Garcia et al., 1998; Hansell and Carlson, 2001; Jenkins, 1980), from sediment traps (Lomas et al., 2010; Stanley et al., 2004; Steinberg et al., 2001), and from ${ }^{234}$ Th disequilibrium (Buesseler et al., 2008; Maiti et al., 2010) .

Here, we present $\mathrm{T}$ and ${ }^{3} \mathrm{He}$ data collected at roughly monthly resolution between 2003 and 2006. In Sect. 2, we describe the data collection, the transit time distribution approach, and the method for calculating AOUR. In Sect. 3, we present the ventilation ages, AOU, and AOUR at the BATS site as well as the depth-integrated AOUR as a measure of export flux. In Sect. 4, we discuss the implications of local versus regional export approaches, the depth and spatial distribution of AOUR, a comparison to other estimates of export at BATS, and a comparison to AOUR in the 1970s and 1980s.

\section{Methods}

\subsection{Data collection}

Samples were collected at the Bermuda Atlantic Time-series Study (BATS) site $\left(31.7^{\circ} \mathrm{N} ; 64.2^{\circ} \mathrm{W}\right)$ on core BATS cruises at approximately monthly resolution between April 2003 and April 2006. The BATS site is representative of the oligotrophic subtropical North Atlantic and a wealth of biogeochemical data has been collected there as part of the timeseries study located there (Steinberg et al., 2001).

Tritium samples were collected from Niskin bottles by gravity feeding into $500 \mathrm{~mL}$ or $950 \mathrm{~mL}$ argon-filled flint glass bottles - water samples at depths $<400 \mathrm{~m}$ were typically in $500 \mathrm{~mL}$ bottles while the deeper samples were in the $950 \mathrm{~mL}$ bottles. The bottles were filled with seawater to the "shoulder", leaving approximately 50 to $100 \mathrm{~mL}$ of $\mathrm{Ar}$ "blanket" present in order to minimize exchange with atmospheric water vapour. Samples were collected at the surface, $50 \mathrm{~m}, 100 \mathrm{~m}, 140 \mathrm{~m}, 200 \mathrm{~m}, 250 \mathrm{~m}, 300 \mathrm{~m}$, and $400 \mathrm{~m}$ every month. Additionally, approximately every 3 months, samples were collected at an additional 22 depths between $500 \mathrm{~m}$ and $4200 \mathrm{~m}$.

The bottles were returned to the Isotope Geochemistry Facility (IGF) at Woods Hole Oceanographic Institution (WHOI) where, on a high-vacuum line, the samples were transferred using negative pressure under an Ar "blanket" to approximately half-fill $200 \mathrm{~mL}$ or $500 \mathrm{~mL}$ pre-evacuated aluminosilicate glass bulbs. The water was then degassed by alternating six 15 minute periods of shaking with six 4 min periods of pumping. The bulbs were flame-sealed and stored in the basement of the laboratory building to shield them from cosmogenic production of ${ }^{3} \mathrm{He}$ during the decay period. For more details on the degassing procedure, see Lott and Jenkins (1998).

After waiting at least six months for ingrowth of ${ }^{3} \mathrm{He}$ from tritium decay, the samples were analysed on a purposefully constructed, branch tube, statically operated, dual-collector magnetic sector helium isotope mass spectrometer, radius of $25.4 \mathrm{~cm}$, equipped with a Faraday cup and a pulse counting secondary electron multiplier. The concentration of tritium in the sample was determined using the radioactive decay equation, the storage time and the amount of ${ }^{3} \mathrm{He}$ measured. Tritium results are expressed in Tritium Units (TU), where

$\mathrm{TU}=\frac{\text { Tritium atoms }}{\text { Hydrogen atoms }} \times 10^{18}$

Helium-3 samples were collected from the same Niskin bottles by gravity feeding through tygon tubing into valved $90 \mathrm{~mL}$ stainless steel sample cylinders. We extracted gases from the water stored in the cylinders into $\sim 30 \mathrm{ml}$ aluminosilicate glass bulbs at an on-shore laboratory within $24 \mathrm{~h}$ of sampling (Lott and Jenkins, 1998). We then brought the bulbs to the IGF at WHOI, where we attached the samples to a dual mass spectrometric system and analysed them for ${ }^{3} \mathrm{He}$, 


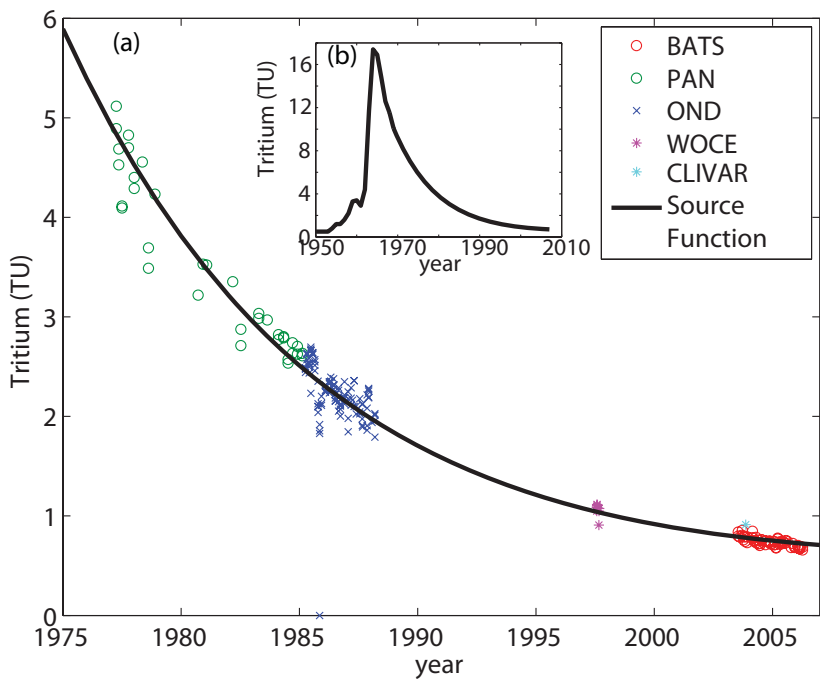

Fig. 1. (a) Surface tritium data collected from 1975 to 2006 at locations near the BATS site, shown in symbols, were compiled to derive a tritium source function appropriate for the BATS study site (solid black curve). See text for an explanation of the data labels. (b) Inset shows the source function from 1950, which includes a modified form of the Dreisigacker and Roether (Dreisigacker and Roether, 1978; Doney and Jenkins, 1988) source function for the years prior to 1969 .

as well as a suite of noble gases $(\mathrm{He}, \mathrm{Ne}, \mathrm{Ar}, \mathrm{Kr}$, and $\mathrm{Xe}) \mathrm{ac}-$ cording to Stanley et al. (2009). In particular, ${ }^{3} \mathrm{He}$ was measured on a purposefully constructed magnetic sector mass spectrometer, similar in design to that used to measure tritium.

Oxygen concentrations were measured on samples from the same Niskin bottles by Winkler titration according to standard BATS procedures (Knap et al., 1997).

\subsection{Calculation of age of water}

The mean age of the water was calculated from the tritium and ${ }^{3} \mathrm{He}$ data using a transit time distribution (TTD) approach (Waugh et al., 2003). In order to do so, we first created an updated surface water tritium source function for BATS. We used the Dreisigacker and Roether (1978) source function in a slightly corrected version until 1969 (Doney and Jenkins, 1988). From 1969 onwards, we determined a source function by fitting a combined exponential and linear function to surface tritium data collected near the BATS site as part of Panulirus (1975 to 1984) (Jenkins, 1998), OND (1982 to 1986) (Jenkins, 1998), WOCE A22 (1997) (http://cchdo.ucsd.edu/), CLIVAR Repeat Hydrography A22 (2003) (http://cchdo.ucsd.edu/), this project (20032006) and the 1969 Dreisigacker and Roether value (Fig. 1). We included the 1969 Dreisigacker and Roether value so there would not be a discontinuity in the function. We also calculated a source function for $t>1969$ not including any data from Dreisigacker and Roether and found that although the coefficients differed slightly, the end result of ages calculated from the source function did not change at all. The best fit function for $t>1969$ was

$$
\begin{aligned}
\mathrm{SF}(\mathrm{TU}) & =9.4594 \times \exp (-0.083 \times(t-1969)) \\
& +0.0095703 \times(t-1969)
\end{aligned}
$$

where SF is the surface tritium concentration, in TU, for fractional year $t$. The coefficients and $1 \sigma$ uncertainties calculated by a Monte Carlos simulation $(n=$ 10000) are $a=10.07 \pm 0.02, b=-0.091 \pm 0.0002$, and $c=0.010 \pm 0.00005$. We realize that using this source function may be an oversimplification since the water collected at depth at BATS (i.e. our samples) did not necessarily surface at BATS itself. There are latitudinal gradients in surface tritium concentrations but the differences are relatively small ( 0.01 to $0.2 \mathrm{TU}$ for 10 degrees difference in latitude), as long as the water surfaces within the subtropical North Atlantic (CLIVAR A20 and A22 Repeat Hydrography Data; Jenkins, 1988; Doney and Jenkins, 1988). In Sect. 4.4, we examine the sensitivity of the results to variations in the source function.

The TTD approach rests on the fact that there is not a single pathway that a water parcel takes between the surface ocean and a given location and depth. Rather, the different water molecules in the parcel have come from different locations, all with different transit times. Thus, instead of assigning a single age to a water parcel, a probability distribution of ages, often of the form of an inverse Gaussian, is used to describe the age of the water parcel. We use the probability distribution and the tritium source function to determine values of $\mathrm{T}$ and ${ }^{3} \mathrm{He}$ associated with different possible mean ages for water collected a given depth and time. We then use our data - the actual $\mathrm{T}$ and ${ }^{3} \mathrm{He}$ measured in a given water sample we collected at BATS - to determine which of these possible mean ages is most suitable for that water parcel. Hence, we determine a mean age for each sample and use this mean age, in concert with the oxygen data, to calculate an AOUR for each sample.

Mathematically, the probability distribution, $G$, we use to describe the continuum of ages, $t$, is the inverse Gaussian (IG) form of the Green's function (Eq. 16 from Waugh et al., 2003):

$G=\sqrt{\frac{\Gamma^{3}}{4 \pi \Delta^{2} t^{3}}} \times \exp \left(-\Gamma \times \frac{(t-\Gamma)^{2}}{4 \Delta^{2} t}\right)$

where $\Gamma$ is defined as the first moment of $G$ and reflects the mean age of the water (Eq. 4 from Waugh et al., 2003):

$\Gamma=\int_{0}^{\infty} t G(t) d t$

and $\Delta$ is defined as the width of $G$ and represents the width of the distribution, i.e. the spread of ages around the mean 
(Eq. 5 from Waugh et al., 2003):

$\Delta^{2}=\frac{1}{2} \int_{0}^{\infty}(t-\Gamma)^{2} G(t) d t$

The IG form is a mathematically convenient analytical form that has previously been used as a good approximation for the TTD in the ocean (Waugh et al., 2003, 2004, 2006). By varying $\Gamma$ and $\Delta$, a wide range of distributions can be chosen from the IG form. Additionally, for the IG, the ratio of $\Gamma / \Delta$ is exactly equal to the square root of the Peclet number in the case of a one-dimensional advection-diffusion equation with constant coefficients.

First, we calculate the probability distributions, $G$, as a function of age, $t$ (ranging from 0 to 200 years), according to Eq. 3 for a series of mean age values, $\Gamma$ from 1 to 100 years. For our base case results, we use the common assumption that $\Gamma / \Delta=1$ (Hall et al., 2004; Waugh et al., 2004; Waugh et al., 2006). Further support for using a $\Gamma / \Delta=1$ stems from Jenkins (1988) showing that the Peclet number is approximately 1 for the subtropical gyre. Since $\Gamma / \Delta$ is equal to the square root of the Peclet number, then $\Gamma / \Delta$ should be 1 as well. Additionally, we use the ${ }^{3} \mathrm{He}$ and $\mathrm{T}$ data from this study as well as from previous studies near BATS and Station $\mathrm{S}$ to constrain that the possible range of $\Gamma / \Delta$ should be between 0.8 and 1.1 , and we perform a sensitivity study for this range (see Sect. 4.4 for more details).

After we calculate the probability distribution $G$ with a range of $\Gamma$ from 1 to 100 and a given $\Gamma / \Delta$, we then convolve $G$, (Eq. 3), with the source function (Eq. 2), which we have decay corrected to the time of sampling, in order to produce a pair of values of $\mathrm{T}$ and ${ }^{3} \mathrm{He}$ for each $\Gamma$. This gives us a lookup table of $\mathrm{T}$ and ${ }^{3} \mathrm{He}$ values that correspond to possible mean ages. Finally, we compare the ${ }^{3} \mathrm{He}$ concentration we measured in the BATS samples to the ${ }^{3} \mathrm{He}$ values calculated for the different possible $\Gamma \mathrm{s}$ in order to determine $\Gamma_{\text {best }}$, the mean age that most appropriately represents that sample. In this manuscript, we refer to this $\Gamma_{\text {best }}$ as $\tau$. Hence, $\tau$ represents the best estimate of the mean age of the water parcel. $\tau$ is sensitive to the choice of $\Gamma / \Delta$ and thus the uncertainty added by the choice of $\Gamma / \Delta$ is included in the uncertainty analysis (see Sect. 4.4). In theory, one could use either the ${ }^{3} \mathrm{He}$ or the tritium data to determine $\tau$; in practice, we found that the ${ }^{3} \mathrm{He}$ data provided a more precise and robust determination, especially on shorter time scales. This is because for a given $\mathrm{T}$ source function, model $\mathrm{T}$ concentrations are relatively insensitive to variations in mean age $(\partial \mathrm{T} / \partial \tau$ is small) for ventilation time scales short relative to the time duration since the bomb-tritium injection event in the early 1960 s (i.e., $\tau<20$ years or so). Thus, the major factor determining model $\mathrm{T}$ concentrations in the upper few meters is the magnitude of the surface $\mathrm{T}$ source function. In contrast, model ${ }^{3} \mathrm{He}$ concentration varies with both mean age $(\tau)$ and $\mathrm{T}$ concentration (and thus source function) and therefore leads to more robust ages. The errors on $\tau$ (grey error bars
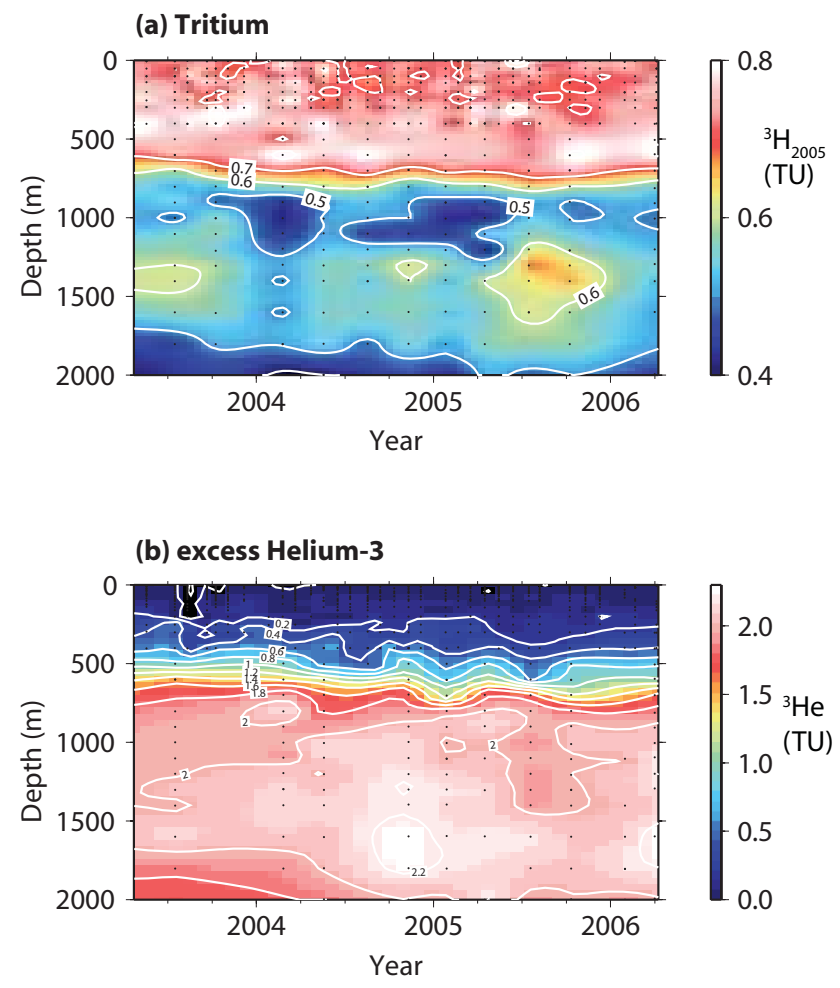

Fig. 2. Three year time-series of (a) tritium and (b) excess ${ }^{3} \mathrm{He}$ from the Sargasso Sea. All tritium data has been decay-corrected to a reference date of 1 January 2005. Black dots reflect locations of data. Contours lines are drawn at every $0.1 \mathrm{TU}$ for ${ }^{3} \mathrm{H}_{2005}$ and every $0.2 \mathrm{TU}$ for ${ }^{3} \mathrm{He}$.

in Fig. 3) are calculated by determining the range of values on the lookup table corresponding to the measurement uncertainty window of the ${ }^{3} \mathrm{He}$ analyses.

We compare the TTD-based results to ages of the water we calculated using a simple box model with a constant ventilation rate (Jenkins, 1980).

\subsection{Calculation of Apparent Oxygen Utilization rates}

Apparent Oxygen Utilization (AOU) is defined as the difference between the equilibrium, or solubility value, of oxygen and the measured concentration:

$\mathrm{AOU}=\left[\mathrm{O}_{2}\right]_{\mathrm{eq}}-\left[\mathrm{O}_{2}\right]_{\text {meas }}$

where $\left[\mathrm{O}_{2}\right]_{\text {eq }}$ is the solubility value for the temperature and salinity of the water sample according to Garcia and Gordon (1992) and $\left[\mathrm{O}_{2}\right]_{\text {meas }}$ is the measured oxygen concentration of the sample. AOU is a measure of how much oxygen has been consumed, assuming that the oxygen concentration was at equilibrium with the atmosphere when the water was at the surface. The surface water probably was not at $100 \%$ saturation because of bubble processes, which increase the degree of saturation, and the effects of atmospheric pressure, which in the water formation regions often decrease the degree of 


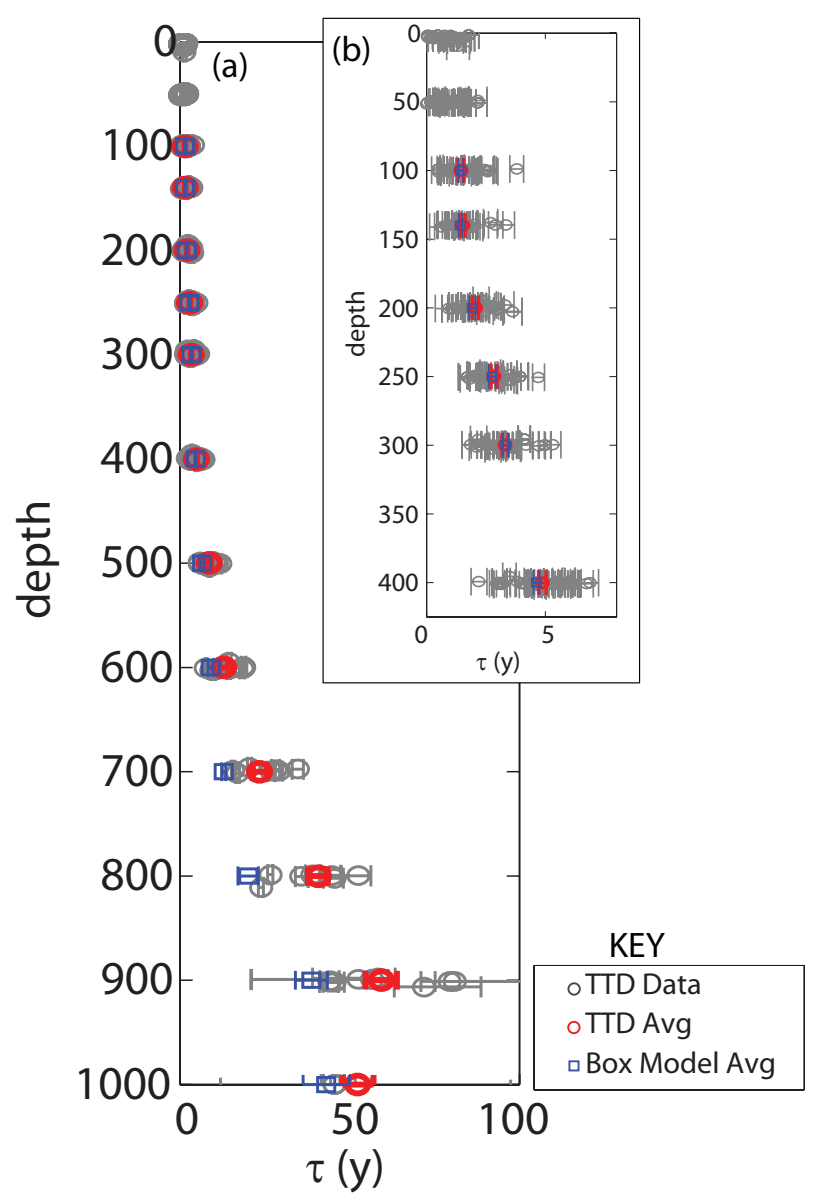

Fig. 3. Water ages $(\tau)$ calculated from a distribution of transit times using ${ }^{3} \mathrm{He}$ data (as described in text) for every sample (gray circles) and as depth averages (red circles) (a) for depths 0 to $1000 \mathrm{~m}$ and (b) only for depths 0 to $400 \mathrm{~m}$. For comparison, depth averages of water ages calculated from a box model approach are also shown (blue squares). Error bars on individual data points reflect $1 \sigma$ uncertainties. Error bars on depth averages reflect standard error of mean of measurements at that depth.

saturation. Still, the water was probably within a few percent of saturation (see Sect. 4.4 for a more precise treatment of this uncertainty).

The Apparent Oxygen Utilization Rate (AOUR), the rate at which oxygen is consumed, is given by

$\mathrm{AOUR}=\frac{\mathrm{AOU}}{\tau}$

By using $\tau$, i.e. the mean age of the water calculated from the TTD approach, in Eq. 7 we are taking into account the probability distribution of the age of the water. Ideally, we would also incorporate the probability distribution of oxygen consumption, i.e. of AOU, but that is not possible given the data that was obtained. In order to do the latter, one would need to exactly know the sources and sinks of oxygen in the ocean interior.
Since the main pathway for oxygen consumption is organic matter respiration, the depth-integrated AOUR is a measure of the export production flux. However, the AOURderived export flux is nonlocal, i.e. it averages over the entire trajectory of the water parcels at each depth, and thus, given the shape of the subtropical gyre, is biased towards remineralization which occurred at shallower depths. It also may be reflecting different regional productivities (see Sect. 4.1). It is useful as a regional measure of export production but is not likely to agree with or balance local measurements of export production, new production, or net community production.

\section{Results}

\subsection{Helium and tritium data}

We present the $\mathrm{T}$ and excess ${ }^{3} \mathrm{He}$ data from the upper $2000 \mathrm{~m}$ in Fig. 2. Although we measured $\mathrm{T}$ and ${ }^{3} \mathrm{He}$ throughout the water column (to $4200 \mathrm{~m}$ depth), only the thermocline and mid-depth data are relevant for this study. The tritium data have been decay-corrected to a reference date of 1 January 2005 , a date in the middle of the time-series. Typical uncertainty on tritium data is $0.008 \mathrm{TU} .{ }^{3} \mathrm{He}$ data were first corrected for any ${ }^{3} \mathrm{He}$ stemming from ingrowth of tritium during the decay period before analysis, a correction on order of $<2 \%$. Excess ${ }^{3} \mathrm{He},{ }^{3} \mathrm{He}_{\mathrm{ex}}$, in number of atoms, is then calculated according to:

$$
\begin{aligned}
{ }^{3} \mathrm{He}_{\mathrm{ex}} & =1.384 \times 10^{-6} \times\left(\frac{{ }^{3} \mathrm{He}}{{ }^{4} \mathrm{He}} \text { meas }-\alpha_{\mathrm{He}}\right) \\
& \times\left[{ }^{4} \mathrm{He}\right] \times \frac{6.023 \times 10^{23}}{22.4 \times 10^{3}}
\end{aligned}
$$

where $1.384 \cdot 10^{-6}$ is the natural isotopic abundance of ${ }^{3} \mathrm{He}$, $\left({ }^{3} \mathrm{He} /{ }^{4} \mathrm{He}\right)_{\text {meas }}$ is the measured ${ }^{3} \mathrm{He} /{ }^{4} \mathrm{He}$ ratio from the samples, $\alpha_{\mathrm{He}}$ is the temperature dependent isotope effect of ${ }^{3} \mathrm{He}$ (Benson and Krause, 1980), $\left[{ }^{4} \mathrm{He}\right]$ is the measured concentration of ${ }^{4} \mathrm{He}$ in the samples, and the constants at the end are the conversions necessary for achieving number of atoms (Avogadro's number and number of moles of gas in $\mathrm{a}^{3}$ ). We then divide the number of ${ }^{3} \mathrm{He}_{\mathrm{ex}}$ atoms by the number of $\mathrm{H}$ atoms in the water sample in order to report excess ${ }^{3} \mathrm{He}$ in $\mathrm{TU}$, just as tritium is reported. Typical uncertainty on excess ${ }^{3} \mathrm{He}$ is 0.02 to $0.03 \mathrm{TU}$.

Tritium concentrations are highest in the subtropical mode water of the main thermocline. In some profiles, there is a second maximum between 1200 and $1600 \mathrm{~m}$ depth. This maximum has been observed previously and has been attributed to a northerly source (Jenkins, 1980). Excess ${ }^{3} \mathrm{He}$ exhibits a maximum between 900 and $2000 \mathrm{~m}$. This is the region where there is still measurable tritium but is below the main thermocline where ${ }^{3} \mathrm{He}$ can be lost upwards due to mixing and then air-sea gas exchange. 


\subsection{Mean age of water: $\tau$}

Profiles of $\tau$, the mean age of the water, are shown in Fig. 3. The profile follows an expected pattern of increasing age with depth. The spread in the ages exceeds analytical uncertainty. This variability is likely a reflection of heaving of isopycnals: the variation of $\tau$ on an isopycnal surface is relatively small but vertical heave of isopycnal surfaces introduces additional variability when using a depth coordinate system. The variability does not show any consistent seasonal pattern at depths greater than $140 \mathrm{~m}$. The trend in mean values appears as a smooth function of depth because the variability averages out over many realizations.

The $\tau$ determined by the TTD approach is very similar to $\tau$ from the box model approach at depths less than or equal to $400 \mathrm{~m}$ (blue symbols in Fig. 3). As the depth increases, the two approaches diverge more. The box model approach gives a younger age since the water mass probability distribution of the box model is exponential whereas in the TTD model, the probability distribution is an IG with a larger age spread (with $\Gamma / \Delta=1$ ).

\subsection{AOU AND AOUR}

Profiles of AOU and AOUR are shown in Fig. 4. AOU increases with depth since the total amount of organic matter that has been remineralized increases with depth. In contrast, AOUR is largest just below the euphotic zone and then decreases with depth. The depth distribution of AOUR is shown more clearly on a log-log plot (Fig. 5a). The data are not well described by a single power law (i.e. "Martin curve" (Martin et al., 1987)) (reduced chi-squared $=52$ for data from $140 \mathrm{~m}$ to $1000 \mathrm{~m}$; reduced chi-squared $=31$ for data from $200 \mathrm{~m}$ to 1000 ) but rather are better described by two power laws with a break at $500 \mathrm{~m}$ (reduced chi-squared $=6$ for data from $140 \mathrm{~m}$ to $1000 \mathrm{~m}$; reduced chi-squared $=2$ for data from $200 \mathrm{~m}$ to $1000 \mathrm{~m}$ ). The exponent of the best power law fit to the $140 \mathrm{~m}$ to $500 \mathrm{~m}$ section of data is -0.12 and the exponent from the best power law fit to the data from $600 \mathrm{~m}$ to $1000 \mathrm{~m}$ is -2.03 . We believe this break corresponds to waters stemming from different origins - the water shallower than approximately $500 \mathrm{~m}$ is primarily mode water which has been directly ventilated from the subtropical North Atlantic recirculation region whereas the deeper water is indirectly ventilated water with a subpolar and Southern Ocean component (Robbins et al., 2000; Talley, 2003) (see Discussion Sect. 4.1 for more details). The $\mathrm{T} /{ }^{\beta} \mathrm{He}$ based method for AOUR is most robust if the water comes from the subtropical North Atlantic since that is the basis for the tritium source function. The Southern Ocean has a very different tritium source function, making the calculations performed here not quantitative for those deeper waters. Ventilation in the subpolar gyre is less of an issue since the source function differs by only $\sim 20 \%$. However, indirect ventilation of the subpolar water may increase the influence of mixing. Therefore, we
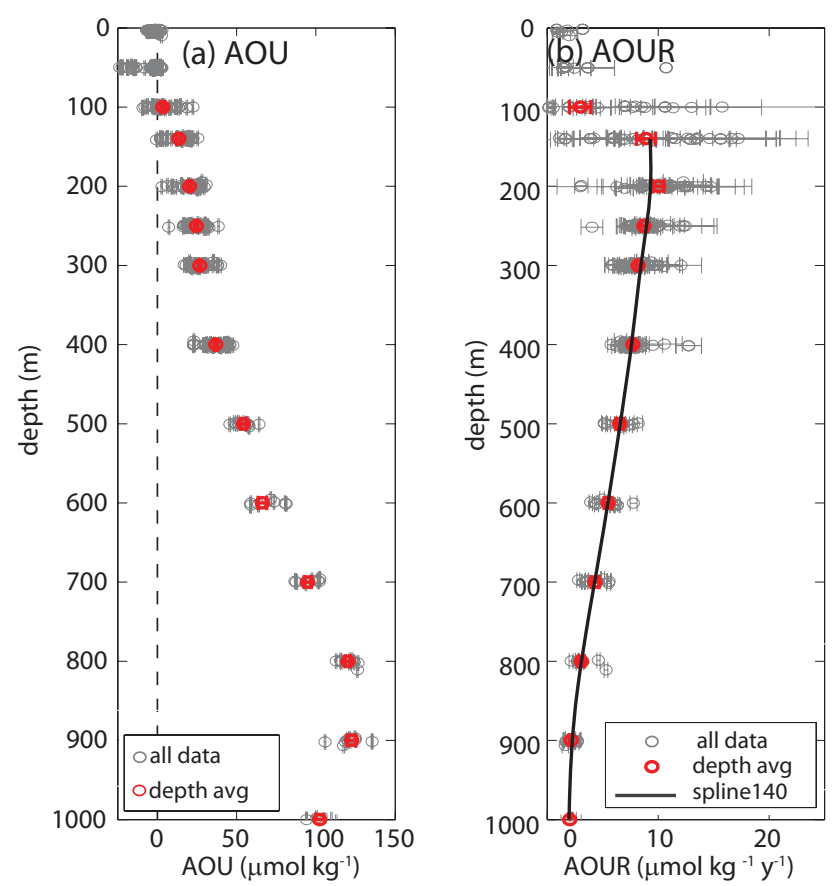

Fig. 4. (a) Apparent Oxygen Utilization (AOU) and (b) AOU Rates (AOUR) as a function of depth at BATS. Gray circles denote all the data collected whereas red circles are depth averages. A spline is fit to the AOUR data from $140 \mathrm{~m}$ to $1000 \mathrm{~m}$ (solid line), and the area under the spline represents the depth-integrated AOUR. Error bars on individual points represent propagated $1 \sigma$ uncertainties and errors on averages reflect $1 \sigma$ standard error of mean from multiple measurements at a given depth.

will concentrate our future discussion on the upper $500 \mathrm{~m}$ of data.

We can vertically integrate the AOUR curve in the upper $500 \mathrm{~m}$ to achieve a minimum estimate of export flux (minimum because it is only reflective of organic matter remineralized in the upper $500 \mathrm{~m}$ ) of $3.1 \pm 0.1 \mathrm{~mol} \mathrm{O}_{2} \mathrm{~m}^{-2} \mathrm{yr}^{-1}$. Using the revised Redfield ratio of 1.45 (Anderson and Sarmiento, 1994), this is equivalent to $2.1 \pm 0.08 \mathrm{~mol} \mathrm{C} \mathrm{m}^{-2} \mathrm{yr}^{-1}$. The error uncertainty represents the $1 \sigma$ uncertainty of the standard error of the mean of AOUR at each depth propagated through the integration. It thus takes into account random variations on monthly timescales and thus is likely to include both analytical uncertainty and environmental variability. However, it does not include the systematic uncertainties in the method such as where the water is really coming from, uncertainties in the source function, or in the surface solubility value of oxygen. Hence, it is likely an underestimate of the true uncertainty in the AOUR-derived, export flux. When a sensitivity study is performed that takes into account uncertainties in the source function, choice of $\Gamma / \Delta$, and surface solubility value of oxygen, the uncertainty in the export flux estimated increases to $0.5 \mathrm{~mol} \mathrm{O}_{2} \mathrm{~m}^{-2} \mathrm{yr}^{-1}$ (see Sect. 4.4). If the box model approach is used to calculate the 

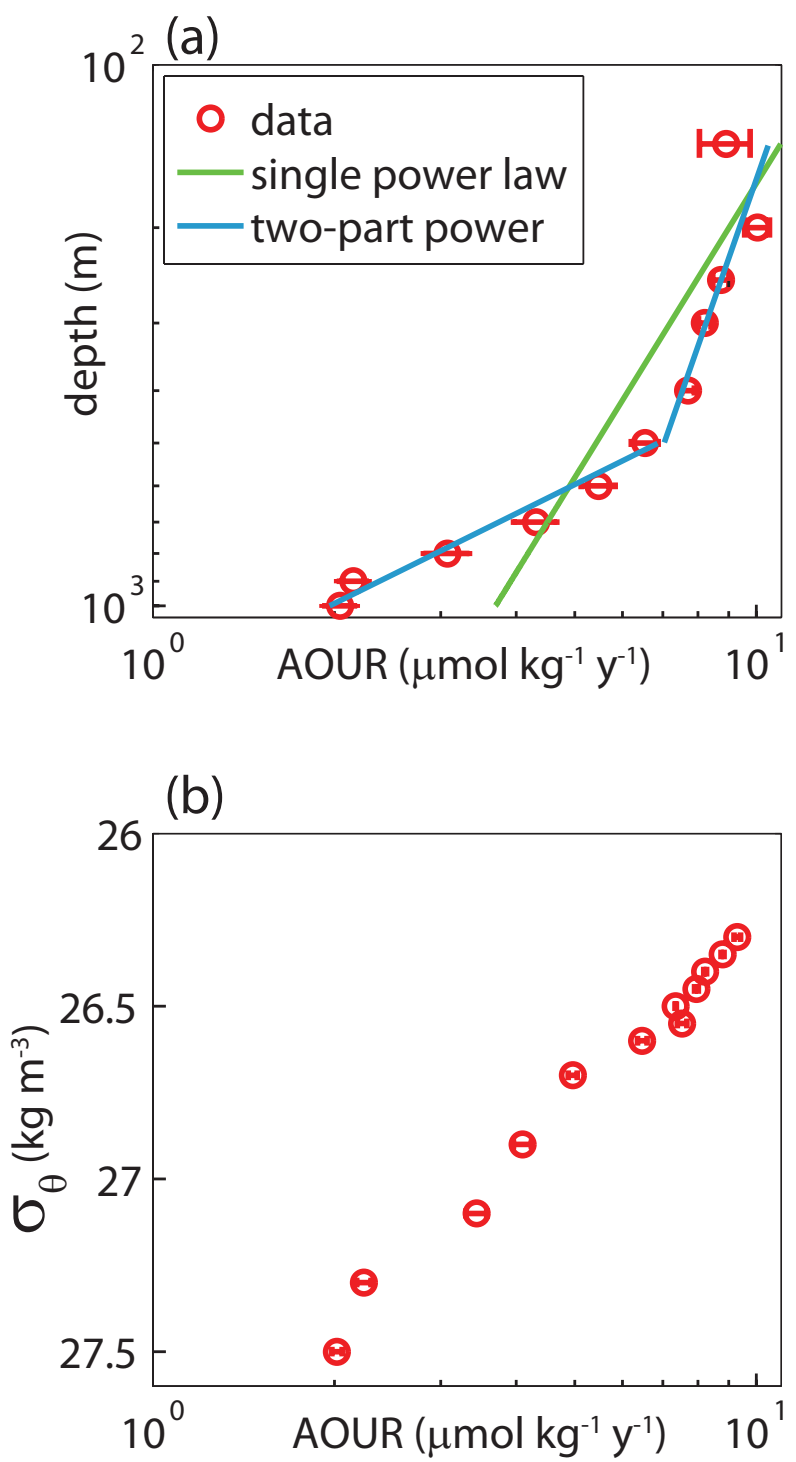

Fig. 5. (a) AOUR averaged on depth surfaces (red circles) plotted vs. depth on a log-log plot. A single power law (green) was not a good fit for all the data so instead a piecewise, two-part power law function with a break at $500 \mathrm{~m}$ was fit to the data (cyan). The equation for the piece-wise fit it is AOUR $=9.67(\mathrm{depth} / 100)^{-0.12}$ for the upper part of the fit and AOUR $=210.58(\mathrm{depth} / 100)^{-2.03}$ for the lower part of the fit. (b) AOUR averaged on density surfaces (red circles) plotted vs. density on a semi-log plot. Note the error bars (1 $\sigma$ standard error of mean) are smaller when AOUR is averaged over density surfaces.

age of the water, then the AOUR-derived export flux is equal to $3.3 \pm 0.1 \mathrm{~mol} \mathrm{O}_{2} \mathrm{~m}^{-2} \mathrm{yr}^{-1}$.

When the data is binned and plotted as a function of density (Fig. 5b), the error bars are much smaller, suggesting much of the variability seen in the plot vs. depth stems from vertical displacement of isopycnals. Because AOUR of a water parcel averages over multiple trajectories along isopycnal surfaces, as well as over the time since the water has been subducted, it is logical that there will be smaller variability when the data is binned on isopycnal surfaces than when it is binned on constant depth horizons. The data in the upper $500 \mathrm{~m}$ corresponds to density surfaces of $\sigma_{\theta}=26.3$ to $26.6 \mathrm{~kg} \mathrm{~m}^{-3}$. Thus we also spatially integrated AOUR along those density surfaces within the recirculation region, i.e. $30^{\circ} \mathrm{N}$ to $45^{\circ} \mathrm{N}, 60^{\circ} \mathrm{W}$ to $75^{\circ} \mathrm{W}$, to obtain an estimate of regional export flux of $3.2 \mathrm{Tmol} \mathrm{O}_{2} \mathrm{yr}^{-1}$, which is equivalent

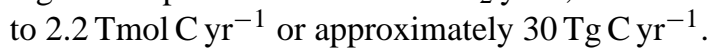

\section{Discussion}

\subsection{Depth and spatial distribution of AOUR}

AOUR reflects the average rate of dissolved and particulate organic matter oxidation along the entire trajectory of a fluid parcel since it left the surface, and trajectories can span a range of depths and regional productivities. Because of the shape of the subtropical gyre and the location of BATS near the deepest part of the subtropical bowl, AOUR measured at a given depth includes the influence of higher oxygen consumption rates when water parcels were, at one time, at a much shallower depth.

One can estimate the approximate effect of this bias by comparing the AOUR along an isopycnal path to the local OUR at a fixed depth and location using reasonable estimates of parcel trajectories. The path-dependent AOUR is simply the OUR averaged in time from the isopycnal outcrop to the sampling location:

$\operatorname{AOUR}\left(z_{\mathrm{obs}}, \tau\right)=\frac{1}{\tau} \int_{0}^{\tau} \operatorname{OUR}(z, t) d t$

where $z_{\text {obs }}$ refers to the depth where the AOUR measurement was taken, and $z$ is the time-varying depth trajectory. If one approximates OUR as the derivative of the Martin et al. (1987) curve and assumes that the depth of the isopycnal increases linearly with time, then one can estimate that AOUR is approximately a factor of 1.5-2.0 larger than the local OUR at the sampling depth $z_{\text {obs }}$. If one uses a non-linear model where isopycnal depths deepen quickly after subduction and then flatten, then the AOUR is approximately a factor of 1.25-1.5 larger than the local OUR at the sampling depth $z_{\text {obs }}$. A more thorough mathematical treatment of the differences between AOUR and OUR is the subject for a future paper.

There is a distinct break in the AOUR data at $\sim 500 \mathrm{~m}$ (Fig. 5a), which likely stems from water shallower than $500 \mathrm{~m}$ being primarily 18 degree mode water that has formed within the subtropical gyre whereas deeper water has a subpolar and southern ocean component (Robbins et al., 2000; Talley, 2003). The water at BATS shallower than $500 \mathrm{~m}$ corresponds to density surfaces of 26.3 to $26.6 \mathrm{~kg} \mathrm{~m}^{-3}$. The March density outcrops, as calculated from World Ocean 


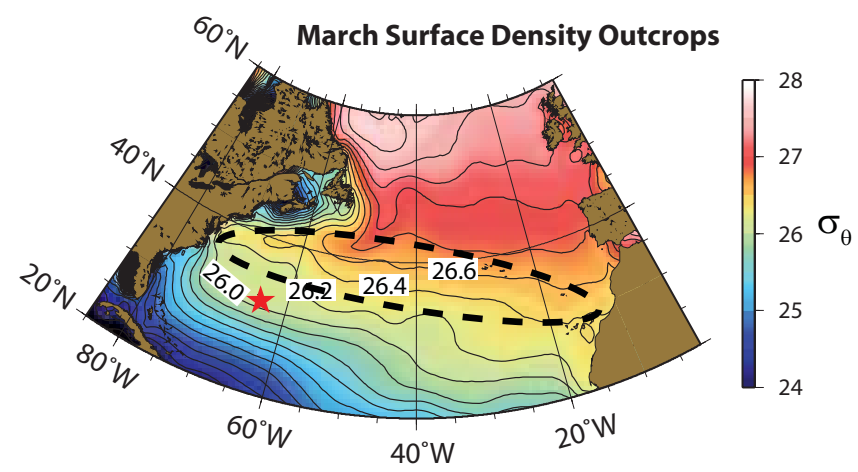

Fig. 6. March surface density outcrops, as calculated from temperature and salinity data from the World Ocean Atlas (Antonov et al., 2009; Locarnini et al., 2009) for the North Atlantic. The location of the BATS site is marked by a red star. Integrated AOUR in the upper $500 \mathrm{~m}$ calculated at BATS is reflective of the region of outcrop of density surfaces of 26.3 to $26.6 \mathrm{~kg} \mathrm{~m}^{-3}$, roughly indicated by the black dashed line.

Atlas Data (Locarnini et al., 2009; Antonov et al., 2009), are shown in Fig. 6. One can clearly see that the density surfaces of 26.3 to $26.6 \mathrm{~kg} \mathrm{~m}^{-3}$ cover a broad area to the north of BATS. Thus, even though we can report an export flux calculated from integrated AOUR at BATS, the flux is representing a much larger geographical area than just BATS. Nonetheless, given the outcrop region, a tritium source function derived for the subtropical North Atlantic is suitable. In contrast, the water deeper than $500 \mathrm{~m}$, i.e. on density surfaces greater than $26.6 \mathrm{~kg} \mathrm{~m}^{-3}$, outcrops further to the north (Fig. 6) as well as in the Southern Ocean.

A second way of determining where the water is coming from is to look at maps of the origin of water derived using the transport matrix method based on model simulations (Khatiwala, 2007) or using a total transport matrix method based on tracer observations (Gebbie and Huybers, 2010). Such maps confirm that the water above $500 \mathrm{~m}$ at BATS is sourced primarily from the local recirculation region whereas the water below $500 \mathrm{~m}$, however, stems from further afield. In particular, a significant component of the water at depths $>800 \mathrm{~m}$ stems from the Southern Ocean. Since the tritium input to the Southern Ocean is so different than that to the North Atlantic, this Southern ocean component makes quantitative interpretation of the deep data difficult.

Since AOUR integrates over the entire trajectory of a water parcel along an isopycnal, it makes more sense to plot AOUR as a function of density, rather than as depth (Fig. 5b). There is limited variability on density surfaces at the fixed spatial location of BATS, as shown by the small standard errors when the AOUR data is binned by density surface. This may be because the inherent averaging time of the AOUR approach (related to the age of the water, which ranges from 2 to 5 years in the upper $500 \mathrm{~m}$ and much longer below that) is similar to or longer than the time period of our study ( 3 years). Or it may be because of internal feedbacks that re- sult in ventilation being tied to respiration rates. The water mass formation processes that serve to ventilate/subduct water also tend to bring subsurface nutrients to the euphotic zone by mixing. As ventilation times increase, fewer nutrients may be replenished in the mixed layer, leading to decreased primary production and possibly decreased remineralization rates. Hence $\tau$ would increase but AOU would decrease and thus the AOUR would remain similar.

Export flux is often approximated as a power law distribution with depth based on empirical analyses of sediment trap data (Martin et al., 1987). Since AOUR is equal to the vertical derivative of the export flux, one might expect it to follow a power law as well. However, because AOUR integrates over an entire isopycnal, which was at a shallower depth earlier, the Martin et al. (1987) model is likely not a good one for AOUR. Nonetheless, one can plot the AOUR on a log-log plot and if a power law is a good model, then the data will fall on a straight line. The best fit single power law of the AOUR data presented here (Fig 5a) has an exponent of -0.55 , which is equivalent to a "Martin curve" exponent for export of 0.45 (since AOUR is the derivative of export, the Martin exponent $=$ AOUR exponent +1$)$. A positive Martin exponent would necessitate some initial export flux that does not change with depth in order to avoid the unphysical situation of a negative export flux. In contrast, the Martin et al. (1987) open ocean composite exponent is -0.858 . If one plots sediment trap data from the Sargasso Sea, one can see that the Martin et al. (1987) curve is not a good fit, with a significant range in flux being apparent at each depth (sediment trap data available at http://bats.bios.edu/).

In spite of the discussion above, one can clearly see that the BATS AOUR data are not described well by a single power law (Fig. 5a) and thus comparing the exponent to Martin et al. (1987) is not particularly fruitful. There are several possible explanations. Most significantly, as described above, the AOUR derived export flux represents a large geographical area including regions which may be much higher in productivity. In contrast, the Martin et al. (1987) curve was constructed from sediment trap data as a local estimate of particle sinking, even including the concept that traps sample a spatially larger "statistical funnel" (Siegel et al., 2008; Siegel and Deuser, 1997). Additionally, recent work has suggested that a power law may often not be a good approximation of export flux in the mesopelagic (Lam et al., 2011), and many studies have found large geographic and temporal variability of mesopelagic flux attenuation (Lee et al., 2009;Lomas et al., 2010;Lutz et al., 2007).

\subsection{Comparison to other estimates of export at BATS}

There is a longstanding disagreement over the magnitude of biological production at the BATS site (Michaels et al., 1994). Geochemical tracer based estimates of export production, net community production, and new production suggest biological production is several times to an order of magni- 
tude higher than estimates based on sediment traps or bottle incubations. This disagreement occurs not only at BATS but also at the Hawaii Ocean Time-series (HOT) and other locations (Burd et al., 2010) and has often been attributed to geochemical estimates averaging over longer spatial and temporal scales than sediment traps or bottle incubations and thus geochemical estimates being more likely to catch episodic high-flux events. AOUR indeed averages over a long spatial and temporal scale - larger scales even than some of the other geochemical techniques such as upper ocean net oxygen and argon balances (Craig and Hayward, 1987; Emerson, 1987; Spitzer and Jenkins, 1989) or DIC balances (Keeling et al., 2004; Quay and Stutsman, 2003) for net community production.

When comparing the estimate of export flux from depthintegrated AOUR reported in this study to other estimates of export flux at BATS (Table 1), one must remember several confounding issues: (1) The AOUR-derived export flux represents the export over a large spatial scale and is reflecting the higher productivity regions. (2) We calculate export flux by vertically integrating AOUR over the upper $500 \mathrm{~m}$ and thus we neglect particles that sink through $500 \mathrm{~m}$ and are remineralized below. Therefore, we are underestimating the total export flux (i.e. export remineralized throughout the entire water column), perhaps by $20 \%$ (Buesseler et al., 2007). (3) The AOUR method includes the effect of export in dissolved form, i.e. remineralization of DOC, whereas some of the other export techniques (sediment traps and ${ }^{234} \mathrm{Th}$ for example) do not. In the subtropical North Atlantic, DOC has been estimated to account $5 \%$ to $28 \%$ of the export flux (Hansell et al., 2004).

The export flux calculated by vertically integrating the AOUR in the upper $500 \mathrm{~m}$, as reported in this study, is about double the flux calculated from averaging the $150 \mathrm{~m}$ sediment trap data from the BATS program (data available at http://bats.bios.edu) over the same 3 year period that the $\mathrm{T}$ and ${ }^{3} \mathrm{He}$ data were collected. This difference is too large to likely be accounted for by DOC remineralization and is consistent with the finding that geochemical techniques usually give larger export fluxes than local ones, likely because of averaging over larger spatial and temporal scales.

Export flux has been measured at BATS through the use of ${ }^{234}$ Th (e.g. Buesseler et al., 1994). A recent study by Brew et al. (2009), that overlapped in time partially with the AOUR study reported here, quantified carbon export using ${ }^{234} \mathrm{Th}$ to range from $1.3 \pm 0.19$ to $3.91 \pm 0.52 \mathrm{mmol} \mathrm{C} \mathrm{m}^{-2} \mathrm{~d}^{-1}$. If one scales these numbers up to annual numbers, they suggest a range of 0.48 to $1.7 \mathrm{~mol} \mathrm{C} \mathrm{m}^{-2} \mathrm{yr}^{-1}$. The upper end of this range is approaching our AOUR-derived flux. Since the AOUR-derived flux averages over much longer spatial and temporal scales than ${ }^{234} \mathrm{Th}$ (a few years rather than a month), it is reasonable to expect that the AOUR-derived flux would capture more of rare high flux events and thus would be at the upper end of the range or larger than the ${ }^{234} \mathrm{Th}$ flux and also average over geographical areas with higher productivity and thus likely higher export.

The export flux reported here is somewhat smaller than export calculated from AOUR based on tritium-helium data by previous studies. In large part, this is due to our study reporting a lower bound of export $(500 \mathrm{~m}$ only) whereas the other studies reported entire water column fluxes. For example, Jenkins (1980) reported a larger export flux of $3.6 \pm 0.7 \mathrm{~mol} \mathrm{C} \mathrm{m}^{-2} \mathrm{yr}^{-1}$. However, when we use a subset of the same data but calculate it using the TTD approach and most significantly only using the upper $500 \mathrm{~m}$, we achieve a number of $1.0 \pm 0.4 \mathrm{~mol} \mathrm{C} \mathrm{m}^{-2} \mathrm{yr}^{-1}$, which is smaller than the export flux determined in this study (see Sect. 4.3 for an in-depth comparison of changing AOUR through time). The export flux we report is in the middle of two other estimates of export flux based on AOUR, which were both calculated using standing stocks of oxygen (Garcia et al., 1998;Hansell and Carlson, 2001).

\subsection{Apparent AOUR changes through time}

The oxygen content of the ocean has been reported to be decreasing (Stramma et al., 2008, 2010; Whitney et al., 2007). Is this decrease due to physical mechanisms, i.e. changes in ventilation, or to biogeochemical ones, i.e. changes in export flux? AOUR is a tool that can help us answer this question since it allows calculation of the water age $(\tau)$ as well as the biological oxygen demand (AOU). Thus we did a detailed comparison between AOUR reported in this paper and AOUR from 20 to 30 years ago. For the older time period, we used tritium and helium data collected in the 1970s and 1980 s at the Station S site $\left(32^{\circ} 10^{\prime} \mathrm{N}, 64^{\circ} 30^{\prime} \mathrm{W}\right)$, which is 15 nautical miles from the BATS site (Jenkins, 1980, 1988, 1998). When Jenkins published the data, he used a box model approach to calculate $\tau$. Here, we applied the same TTD approach that we used for the 2003 to 2006 data (described in Sect. 2.2) to ensure that any differences in $\tau$ were not the result of calculation methods. We found that AOUR in 2003 to 2006 was significantly greater than AOUR in the 1970s and 1980s (Fig. 7a). This difference was most pronounced in the upper $500 \mathrm{~m}\left(\sigma_{\theta}<26.6 \mathrm{~kg} \mathrm{~m}^{-3}\right)$, the area where we have the most confidence in our approach.

What is the cause for this increase in AOUR with time? When we look at the AOUR in terms of its two components - AOU and $\tau$ (Fig. 7b and c), we see that $\tau$ is the same, within errors, in the two time periods but that AOU was significantly lower in 1977-1987 than in 2003-2006. Thus the change in AOUR is not due to physical changes in ventilation but rather due to the biogeochemical changes associated with a changing AOU. The change in AOU could be due to changes in export associated with climate change or climate variability or could be due to methodological artefacts.

Examination of the deep oxygen record (2100 to $2700 \mathrm{~m}$ ) from Station S and BATS over the last thirty years supports the conclusion that the difference in AOU is likely due to 
Table 1. Estimates of export flux from this and other studies.

\begin{tabular}{lll}
\hline Flux $\left(\mathrm{mol} \mathrm{C} \mathrm{m}^{-2} \mathrm{yr}^{-1}\right)$ & Method & Reference \\
\hline $2.1 \pm 0.5$ & AOUR: T and ${ }^{3} \mathrm{He}$ & this study \\
$3.6 \pm 0.7$ & AOUR: $\mathrm{T}$ and ${ }^{3} \mathrm{He}$ & Jenkins, 1980 \\
4.6 to 5.5 & AOUR: $\mathrm{O}_{2}$ stocks & Hansell and Carlson, 2001 \\
0.9 & AOUR: $\mathrm{O}_{2}$ stocks & Garcia et al., 1998 \\
0.9 & Sediment Traps & BATS data: 2003 to 2006* \\
0.5 to 1.7 & ${ }^{234} \mathrm{Th}$ & Brew et al., 2009 \\
\hline
\end{tabular}

* Sediment trap data from the BATS data website: http://bats.bios.edu/
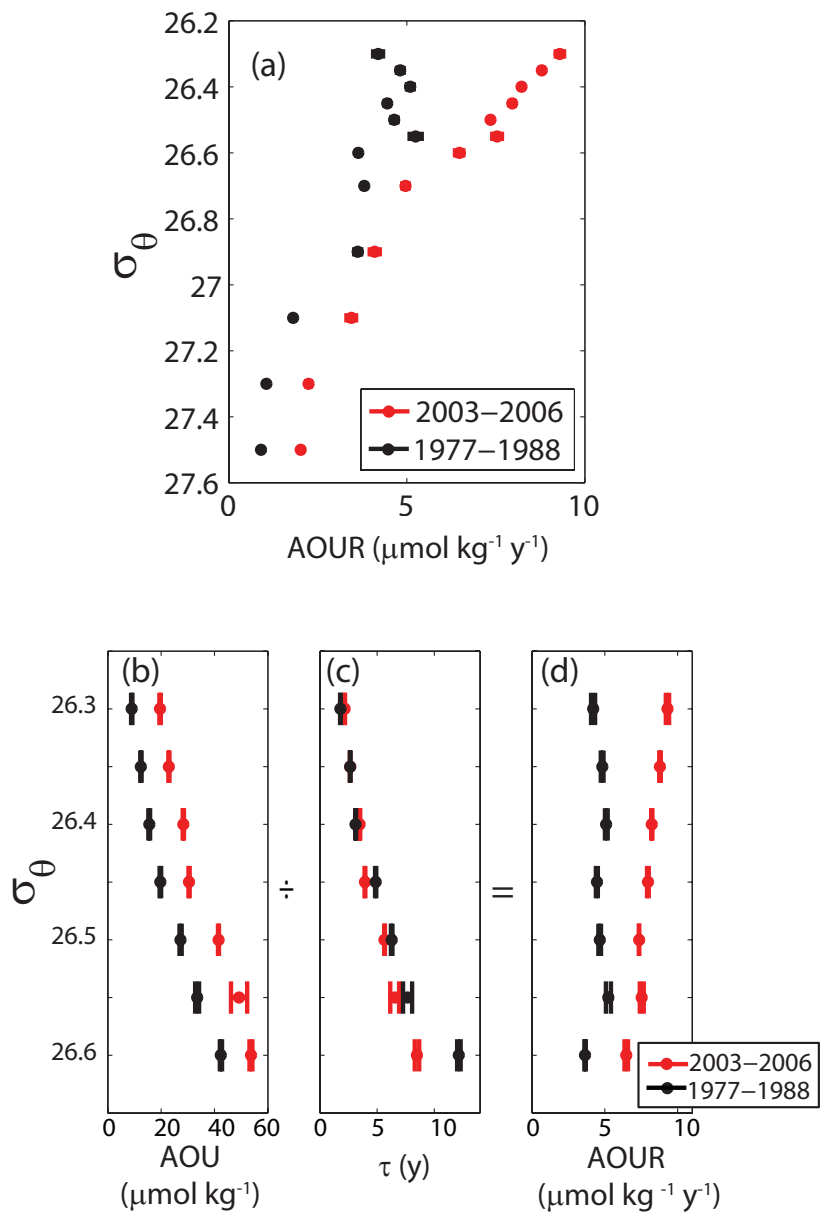

Fig. 7. Comparison of estimates from 2003-2006 (red) and 19771988 (black) of (a) AOUR averaged over isopycnal surfaces in the upper $1200 \mathrm{~m}$ of the water column and of (b) AOU, (c) water age $(\tau)$ and (d) AOUR over isopycnal surfaces from 26.3 to $26.6 \mathrm{~kg} \mathrm{~m}^{-3}$ (upper $500 \mathrm{~m}$ only). Note the difference in AOUR between the two time-periods, especially in the upper $500 \mathrm{~m}$. This difference is due to changes in AOU, not to changes in $\tau$.

methodological artefacts (Fig. 8). Oxygen in these deep waters should not change much with time given the long residence time of oxygen below the range of most organic mat-

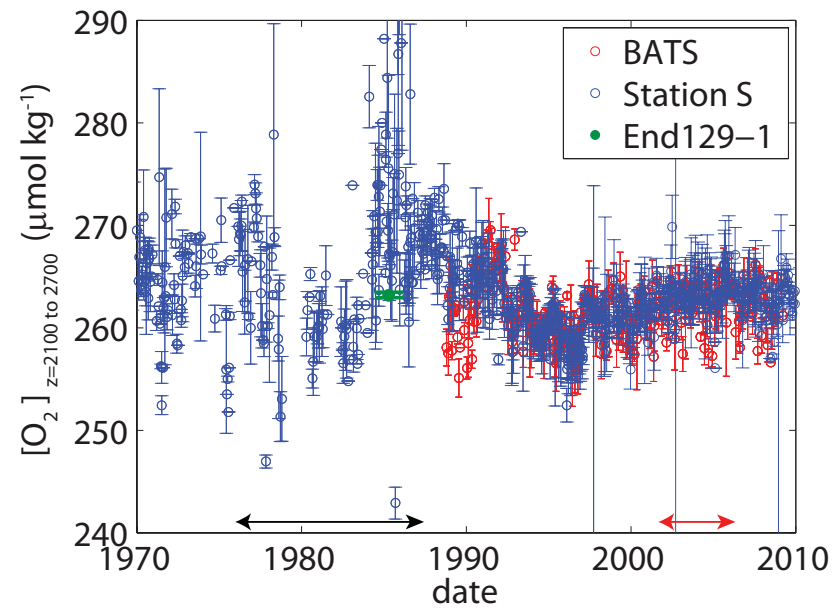

Fig. 8. Deep $\mathrm{O}_{2}$ concentrations (mean of $z=2100$ to $2700 \mathrm{~m}$ ) from BATS (blue) and Station $\mathrm{S}$ (red). Note the scattered and high $\mathrm{O}_{2}$ values in Station $\mathrm{S}$ data before 1992, especially in the period between 1985 and 1988. The black and red arrows represent the time-periods of the "old" and "new" AOUR data compared in the text. For comparison, deep $\mathrm{O}_{2}$ concentration (mean of $z=2100$ to 2700) from station 50 on the Endeavor 129-1 leg is presented (green), a station that was close to the BATS site and thus presumably should have similar deep oxygen concentrations.

ter remineralization. However, when one looks at the oxygen record, one can see that the deep $\mathrm{O}_{2}$ data from Station $S$ in the 1970s and 1980s is much more scattered and significantly greater than the deep BATS data or Station S data from 1992 onwards. In particular, the time period between 1985 and 1987 has particularly large deep $\mathrm{O}_{2}$ concentrations, which are on average $9.8 \mu \mathrm{mol} \mathrm{kg}{ }^{-1}$ larger than during 2003-2006. If these variations in deep $\mathrm{O}_{2}$ concentrations were a result of real oceanographic processes, then they would likely be correlated with temperature and salinity, since in this domain higher oxygen is related to lower temperature and salinity. However, a correlation analysis between the deep $\mathrm{O}_{2}$ concentrations before 1988 and salinity shows no correlation $\left(R^{2}=0.03, P=0.14\right)$. In contrast, a correlation analysis between the deep $\mathrm{O}_{2}$ concentrations at Station S after 1992 and salinity show a weak negative 
correlation $\left(R^{2}=0.1, P=0\right)$. Furthermore, $\mathrm{O}_{2}$ concentrations from a location near Station $\mathrm{S}\left(32.332^{\circ} \mathrm{N}, 64.200^{\circ} \mathrm{W}\right)$ performed by a different lab as part of station 50 on the $\mathrm{R} / \mathrm{V}$ Endeavor 129-1 cruise, yield deep $\mathrm{O}_{2}$ concentrations in 1985 of $263.2 \pm 0.2 \mu \mathrm{mol} \mathrm{kg}^{-1}$ (Knapp, 1988), which is very similar to the 2003 to 2006 BATS deep $\mathrm{O}_{2}$ concentrations $\left(262.2 \pm 2 \mu \mathrm{mol} \mathrm{kg}{ }^{-1}\right)$ but significantly lower than the 1985 Station $\mathrm{S} \mathrm{O}_{2}$ data $\left(274 \pm 12 \mu \mathrm{mol} \mathrm{kg}{ }^{-1}\right)$.

The high degree of variability in the old Station $\mathrm{S}$ data data (i.e. older than 1990 data) which is not correlated with other oceanographic variables, as well as the on average larger $\mathrm{O}_{2}$ concentrations, suggest that the Station $\mathrm{S} \mathrm{O}_{2}$ data in the 1980s suffers from methodological artefacts. Potential methodological artefacts include gas leaks because the seawater was collected in Nansen bottles, as opposed to the more gas-tight niskin bottles that seawater is now collected in, as well as potential bubble entrainment when collecting samples and dispensing solutions necessary for the oxygen titration.

The fact that the apparent differences in AOUR between 2003 and 2006 and the 1980s as reported here is likely due to methodological artefacts suggests that caution should be used when $\mathrm{O}_{2}$ inventories are compared at other locations as well. Old $\mathrm{O}_{2}$ data from other locations may have methodological artefacts as well and should be examined carefully before conclusions on ocean deoxygenation are made.

\subsection{Uncertainties and sensitivity studies}

There are a number of sources of uncertainty in the AOUR estimates and export flux reported in this paper. Here we perform a sensitivity study of the depth-integrated AOUR to some of the parameters used in the calculations. We then discuss some other sources of errors that are not easily quantifiable.

For water shallower than $500 \mathrm{~m}$, the source of the water is likely the subtropical North Atlantic recirculation region, and thus a tritium source function centered at BATS is a good approximation. However, we still do not know exactly where within the recirculation region the water surfaced and thus we examine the sensitivity of our results to changes in the source function. There is approximately a $10 \%$ increase in tritium for every 10 degrees north of Bermuda (Doney and Jenkins, 1988). If the source function is $10 \%$ larger, than the export flux increases to $3.3 \pm 0.1 \mathrm{~mol} \mathrm{O}_{2} \mathrm{~m}^{-2} \mathrm{yr}^{-1}$, a $8 \%$ increase (Table 2). This suggests that the error added by the source function, in water shallower than $500 \mathrm{~m}$, is less than $10 \%$. For waters deeper than $500 \mathrm{~m}$, the problem is more severe. Some fraction of the deeper water is sourced from the Southern Ocean where there is likely a very different tritium source function, given that the tritium loading was primarily in the Northern hemisphere (Doney et al., 1992). We thus do not perform a quantitative interpretation of our deeper data in this paper; that will be the topic of a future paper.
Table 2. Sensitivity study of depth-integrated $\mathrm{O}_{2}$ consumption rate to reasonable choices of parameters.

\begin{tabular}{lll}
\hline & $\begin{array}{l}\text { Integrated } \\
\mathrm{O}_{2} \\
\text { consumption } \\
\text { rate in upper } \\
500 \mathrm{~m}^{*}\end{array}$ & $\begin{array}{l}\% \\
\text { difference } \\
\text { from base } \\
\text { case }\end{array}$ \\
& $3.1 \pm 0.1$ & - \\
& $3.2 \pm 0.1$ & $4 \%$ \\
\hline Base case & & \\
Source Function $(\mathrm{SF})$ & $3.4 \pm 0.1$ & $8 \%$ \\
$+5 \%$ & $3.3 \pm 0.1$ & $5 \%$ \\
$\mathrm{SF}+10 \%$ & $3.1 \pm 0.1$ & $2 \%$ \\
$\Gamma / \Delta=0.8$ & $2.9 \pm 0.1$ & $-6 \%$ \\
$\Gamma / \Delta=1.1$ & $2.6 \pm 0.1$ & $-15 \%$ \\
$\Gamma / \Delta=1.3$ & $3.4 \pm 0.1$ & $10 \%$ \\
$\Gamma / \Delta=2.0$ & $3.1 \pm 0.1$ & $1 \%$ \\
$\mathrm{SF}+5 \%$ and $\Gamma / \Delta=0.8$ & $2.8 \pm 0.1$ & $-11 \%$ \\
$\mathrm{SF}+5 \%$ and $\Gamma / \Delta=1.1$ & $3.3 \pm 0.1$ & $3 \%$ \\
$\mathrm{SF}+5 \%$ and $\Gamma / \Delta=2.0$ & $2.9 \pm 0.1$ & $-6 \%$ \\
$\mathrm{Box}$ model approach for $\tau$ & $3.5 \pm 0.1$ & $13 \%$ \\
$\mathrm{O}_{2}$ initial saturation $=101.5 \%$ & \\
$\mathrm{O}_{2}$ initial saturation $=99 \%$ & & \\
\hline
\end{tabular}

* Units of oxygen consumption rate (equivalent to export flux) are $\mathrm{mol}_{2} \mathrm{~m}^{-2} \mathrm{yr}^{-1}$ Uncertainties listed equal the standard error of the mean of AOUR at a given depth propagated through the integration.

A second issue to consider when calculating $\tau$ is that the results are sensitive to the choice of $\Gamma$ and $\Delta$. Since we have two transient tracers - both $\mathrm{T}$ and ${ }^{3} \mathrm{He}$ - we use the data shallower than $500 \mathrm{~m}$ (density less than $26.6 \mathrm{~kg} \mathrm{~m}^{-3}$ ) and the TTD equations in order to constrain the ratio of $\Gamma / \Delta$ (Fig. 9). To do this, we plot in ${ }^{3} \mathrm{He} / \mathrm{T}$ space the ensemble of points determined by a range of $\Gamma$ but a fixed $\Gamma / \Delta$ (curves in Fig. 9) and also all the shallow data from BATS (symbols in Fig. 9). We can thus determine which $\Gamma / \Delta$ give an ensemble that overlaps with the data. We use all the shallow data since that data has a range of $\Gamma$ and origins fitting within the source function (Eq. 2). Specifically, we use a range of $\Gamma$ from 0 to 200 , apply different $\Gamma / \Delta$ ratios (e.g. 0.8, 0.9, $1,1.1,2)$ to calculate $\Delta$, and then calculate $G$ according to Eq. 3. We next use the source function (Eq. 2), which has been decay corrected, and $G$ in order to calculate ${ }^{3} \mathrm{He}$ and $\mathrm{T}$ values. We plot those ${ }^{3} \mathrm{He}$ and $\mathrm{T}$ values (colored curves in Fig. 9) alongside the $\mathrm{T}$ and ${ }^{3} \mathrm{He}$ data measured (black squares) in order to determine a range of $\Gamma / \Delta$ that gives a reasonable fit to the data. Using the data from this study, $\Gamma / \Delta$ could range between 0.8 and 2.0. If $\Gamma / \Delta$ is 0.8 , then the export flux increases by $5 \%$ to $3.3 \pm 0.1 \mathrm{molO}_{2} \mathrm{~m}^{-2} \mathrm{yr}^{-1}$ (Table 2). If $\Gamma / \Delta=2.0$, then the export flux decreases by $15 \%$ to $2.6 \pm 0.1 \mathrm{~mol} \mathrm{O}_{2} \mathrm{~m}^{-2} \mathrm{yr}^{-1}$. Using data from previous studies (Jenkins, 1980, 1988, 1998) allows a better constraint since $\mathrm{T}$ and ${ }^{3} \mathrm{He}$ were higher in the upper thermocline during the 1970s and 1980s. The older data further 
(a) 1977-1982

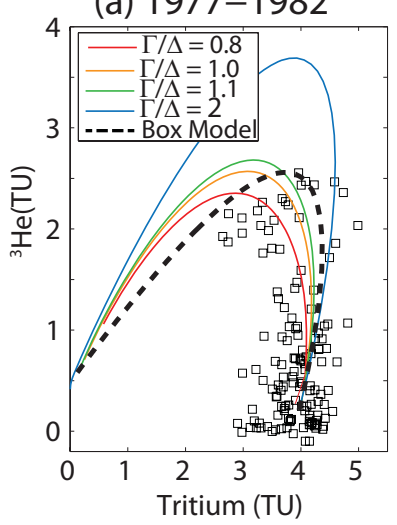

(b) 2003-2006

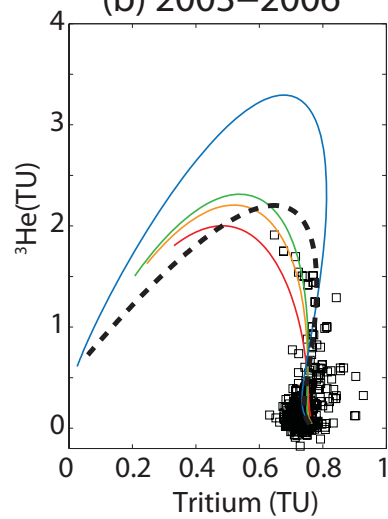

Fig. 9. Tritium and ${ }^{3} \mathrm{He}$ data (black squares) from the upper $500 \mathrm{~m}$ $\left(\sigma_{\theta}<=26.6 \mathrm{~kg} \mathrm{~m}^{-3}\right.$ ) from (a) 1977-1982 and from (b) 2003-2006 (this study) were used to constrain $\Gamma / \Delta$, a ratio necessary for the TTD approach. The curves represent the ensemble of $\Gamma$ in ${ }^{3} \mathrm{He} / \mathrm{T}$ space predicted by the TTD model for a fixed $\Gamma / \Delta$ ratio. For the data presented in this study, a range of $\Gamma / \Delta$ of 0.8 to 2.0 seems reasonable. From the older data, it can be seen that a tighter range of $\Gamma / \Delta$ of 0.8 to 1.1 is more suitable. Also plotted (black dashed line) is the $\mathrm{T}$ and ${ }^{3} \mathrm{He}$ predicted by the box model approach.

constrains $\Gamma / \Delta$ to be between 0.8 and 1.1. If $\Gamma / \Delta=1.1$, the export flux decreases by $3 \%$ to $3.05 \pm 0.1 \mathrm{~mol} \mathrm{O}_{2} \mathrm{~m}^{-2} \mathrm{yr}^{-1}$. The range of 0.8 to 1.1 determined in this fashion is similar to the range of $\Gamma / \Delta$ suggested by studies of CFCs and $\mathrm{T}$ in the North Atlantic of 0.8 to 1.33 (Waugh et al., 2004, 2006). If $\Gamma / \Delta=1.33$, then the export flux decreases by $6 \%$ to $2.9 \mathrm{~mol} \mathrm{O}_{2} \mathrm{~m}^{-2} \mathrm{yr}^{-1}$. Thus a reasonable range of $\Gamma / \Delta$ only changes the integrated export by less than $6 \%$. If instead of using the TTD approach we use the box model approach (Jenkins, 1980), which is shown in Fig. 9 to do a good job at fitting the $\mathrm{T}$ and ${ }^{3} \mathrm{He}$ data, then the depth-integrated AOUR increases by $6 \%$ to $3.3 \pm 0.1 \mathrm{~mol} \mathrm{O}_{2} \mathrm{~m}^{-2} \mathrm{yr}^{-1}$.

An added source of uncertainty stems from the assumption implicit in AOU that the oxygen at the surface was in equilibrium. However, in the surface ocean, oxygen is often not at equilibrium. $\mathrm{O}_{2}$ measurements at BATS can give us an idea of the expected the deviation of $\mathrm{O}_{2}$ from equilibrium. Measurements of $\mathrm{O}_{2}$ in the mixed layer at BATS show that $\mathrm{O}_{2}$ ranges from being undersaturated by approximately $1 \%$ to $2 \%$ in the winter to being supersaturated by $2 \%$ to $3 \%$ in the summer (http://www.bios.bats.edu/). Stommel (1979) argued that a "demon" selectively pumps late winter water into the main thermocline. Modeling experiments confirmed Stommel's hypothesis finding that the subduction period lasts about one month after the end of winter (Williams et al., 1995). In the late winter/early spring at BATS, the $\mathrm{O}_{2}$ saturation ranges from $99 \%$ to $101.5 \%$ depending upon the year (http://www.bios.bats.edu/). If we calculate the depthintegrated AOUR assuming surface water is at $99 \%$ of saturation value, then we determine the depth-integrated AOUR

from 140 to $500 \mathrm{~m}$ to be $2.9 \mathrm{~mol} \mathrm{O}_{2} \mathrm{~m}^{-2} \mathrm{yr}^{-1}$, a decrease of $6 \%$ over our initial calculation. If we use $101.5 \%$ of saturation value, the value is $3.5 \mathrm{~mol} \mathrm{O}_{2} \mathrm{~m}^{-2} \mathrm{yr}^{-1}$, an increase of $13 \%$. Thus uncertainty in the initial saturation value of $\mathrm{O}_{2}$ leads to an uncertainty of approximately $13 \%$ in our calculations.

If we add in quadrature conservative estimates of the uncertainty from the source function $(8 \%)$, choice of $\Gamma / \Delta$ ( $8 \%$, note: we do not include the $\Gamma / \Delta=2$ choice since it is shown to be too pessimistic by earlier data), initial oxygen saturation $(13 \%)$, and measurement uncertainty $(3 \%)$, then the total uncertainty on the depth-integrated AOUR number is $0.5 \mathrm{~mol} \mathrm{O}_{2} \mathrm{~m}^{-2} \mathrm{yr}^{-1}$, a $16 \%$ uncertainty.

A limitation in the calculation of the export flux presented here is that we are only integrating the AOUR between $140 \mathrm{~m}$ and $500 \mathrm{~m}$. Our estimate of export flux does not include remineralization above $140 \mathrm{~m}$. Even at $140 \mathrm{~m}$, there is the question of whether $\mathrm{O}_{2}$ produced in the euphotic zone can be mixed down to $140 \mathrm{~m}$ during winter mixing (winter mixed layer depths at BATS often reach $200 \mathrm{~m}$ ) and thus the AOUR determined at $140 \mathrm{~m}$ is a minimum estimate. Indeed, one can see the effect of this mixing when one looks at the seasonal cycle of AOUR at $140 \mathrm{~m}$, where there is a dramatic decline in AOUR each January.

We did not calculate export production above $140 \mathrm{~m}$ using this approach and yet we know that oxygen consumption is occurring at shallower depths. Export is often defined as organic matter remineralized below the euphotic zone, which would be approximately $100 \mathrm{~m}$ at BATS. A recent study used ${ }^{7} \mathrm{Be}$ to estimate oxygen consumption rates in the upper $200 \mathrm{~m}$ of the ocean at BATS and found a depth-integrated oxygen consumption rate of $4.5 \pm 0.4 \mathrm{~mol} \mathrm{O}_{2} \mathrm{~m}^{-2} \mathrm{yr}^{-1}$ between 100 and $200 \mathrm{~m}$ (Kadko, 2009) - this is comparable to our entire estimate of oxygen consumption from $140 \mathrm{~m}$ to $500 \mathrm{~m}$. It is not possible from the Kadko study to know what proportion of the estimated oxygen consumption occurred between 100 and $140 \mathrm{~m}$ (missed in our study) and which was between 140 and $200 \mathrm{~m}$ (included in our study). Nonetheless, the point remains that there is significant export in the upper $200 \mathrm{~m}$ that we may not be properly accounting for.

\section{Conclusions}

We have presented AOUR for a three year time period at the BATS site as determined by tritium and ${ }^{3} \mathrm{He}$ data. We find that the depth integrated oxygen consumption between $140 \mathrm{~m}$ and $500 \mathrm{~m}$ is $3.1 \mathrm{~mol} \pm 0.5 \mathrm{~mol} \mathrm{O}_{2} \mathrm{~m}^{-2} \mathrm{yr}^{-1}$. This estimate of export is reflective of large spatial and temporal scales the spatial scale is approximately that of the recirculation region and the temporal scale is that of several years. This estimate is a minimum estimate of export since substantial oxygen consumption may be occurring above $140 \mathrm{~m}$ and below $500 \mathrm{~m}$. We sampled at monthly resolution and find very little variation of AOUR when the data is binned on isopycnal 
surfaces, likely a reflection of the long spatial and temporal scales of the measurement but also suggestive of internal feedbacks between ventilation and remineralization.

We compared AOUR presented in this study to AOUR calculated based on earlier tritium and ${ }^{3} \mathrm{He}$ data and found a large increase in AOUR over the past thirty years. Although a simple interpretation of the data would suggest a major change in production or remineralization, such a change is not likely. Instead this increase in AOUR is most likely due to methodological artefacts in the oxygen data from the 1980s. This suggests that historical oxygen data should be used with caution when making interpretations about ocean deoxygenation.

Acknowledgements. We thank three anonymous referees for their suggestions. We are grateful to Mike Lomas, Rod Johnson, the BATS technicians and the captain and crew of the R/V Weatherbird II and R/V Atlantic Explorer for their support in collecting data for this study. Support from this work came from the National Science Foundation (OCE-0221247, OCE-0623034, and OCE-1029676) and from the WHOI Penzance Endowed Fund in Support of Assistant Scientists.

Edited by: G. Herndl

\section{References}

Anderson, L. A. and Sarmiento, J. L.: Redfield ratios of remineralization determined by nutrient data-analysis, Global Biogeochem. Cy., 8, 65-80, 1994.

Antonov, J. I., Seidov, D., Boyer, T. P., Locarnini, R. A., Mishonov, A. V., Garcia, H. E., Baranova, O. K., Zweng, M. M., and Johnson, D. R.: World Ocean Atlas 2009, Volume 2: Salinity, edited by: Levitus, S., U. S. Government Printing Office, Washington D. C., 184 pp., 2009.

Benson, B. B. and Krause Jr, D.: Isotopic fractionation of helium during solution: a probe for the liquid state, J. Solut. Chem., 9, 895-909, 1980.

Bopp, L., Le Quere, C., Heimann, M., Manning, A. C., and Monfray, P.: Climate-induced oceanic oxygen fluxes: Implications for the contemporary carbon budget, Global Biogeochem. Cy., 16, 1022, doi:10.1029/2001gb001445, 2002.

Brew, H. S., Moran, S. B., Lomas, M. W., and Burd, A. B.: Plankton community composition, organic carbon and thorium-234 particle size distributions, and particle export in the Sargasso Sea, J. Mar. Res., 67, 845-868, 2009.

Buesseler, K. O., Michaels, A. F., Siegel, D. A., and Knap, A. H.: A three dimensional time-dependent approach to calibrating sediment trap fluxes, Global Biogeochem. Cy., 12, 297-310, 1994.

Buesseler, K. O., Lamborg, C. H., Boyd, P. W., Lam, P. J., Trull, T. W., Bidigare, R. R., Bishop, J. K. B., Casciotti, K. L., Dehairs, F., Elskens, M., Honda, M., Karl, D. M., Siegel, D. A., Silver, M. W., Steinberg, D. K., Valdes, J., Van Mooy, B., and Wilson, S.: Revisiting carbon flux through the ocean's twilight zone, Science, 316, 567-570, 2007.
Buesseler, K. O., Lamborg, C., Cai, P., Escoube, R., Johnson, R., Pike, S., Masque, P., McGillicuddy, D., and Verdeny, E.: Particle fluxes associated with mesoscale eddies in the Sargasso Sea, Deep-Sea Res. Pt. II, 55, 1426-1444, doi:10.1016/j.dsr2.2008.02.007, 2008.

Burd, A. B., Hansell, D. A., Steinberg, D. K., Anderson, T. R., Aristegui, J., Baltar, F., Beaupre, S. R., Buesseler, K. O., DeHairs, F., Jackson, G. A., Kadko, D. C., Koppelmann, R., Lampitt, R. S., Nagata, T., Reinthaler, T., Robinson, C., Robison, B. H., Tamburini, C., and Tanaka, T.: Assessing the apparent imbalance between geochemical and biochemical indicators of meso- and bathypelagic biological activity: What the @\$\#! is wrong with present calculations of carbon budgets?, Deep-Sea Res. Pt. II 57, 1557-1571, doi:10.1016/j.dsr2.2010.02.022, 2010.

Codispoti, L. A., Brandes, J. A., Christensen, J. P., Devol, A. H., Naqvi, S. W. A., Paerl, H. W., and Yoshinari, T.: The oceanic fixed nitrogen and nitrous oxide budgets: Moving targets as we enter the anthropocene?, Sci. Mar., 65, 85-105, 2001.

Craig, H. and Hayward, T.: Oxygen supersaturation in the ocean: biological versus physical contributions, Science, 235, 199-202, 1987.

Deutsch, C., Brix, H., Ito, T., Frenzel, H., and Thompson, L.: Climate-forced variability of ocean hypoxia, Science, 333, 336339, 2011.

Doney, S. C., and Jenkins, W. J.: The effect of boundary conditions on tracer estimates of thermocline ventilation rates, J. Mar. Res., 46, 947-965, 1988.

Doney, S. C. and Bullister, J. L.: a chlorofluorocarbon section in the eastern north-atlantic, Deep-Sea Res., 39, 1857-1883, doi:10.1016/0198-0149(92)90003-c, 1992.

Doney, S. C., Glover, D. M., and Jenkins, W. J.: A Model Function of the Global Bomb Tritium Distribution in Precipitation 1960-1986, J. Geophys. Res.-Ocean, 97, 5481-5492, doi:10.1029/92jc00015, 1992.

Dreisigacker, E. and Roether, W.: Tritium and ${ }^{90} \mathrm{Sr}$ in North Atlantic surface water, Earth Planet. Sci. Lett., 38, 301-312, 1978.

Emerson, S.: Seasonal Oxygen Cycles and Biological New Production in Surface Waters of the Sub-Arctic Pacific-Ocean, J. Geophys. Res.-Ocean, 92, 6535-6544, 1987.

Garcia, H., Cruzado, A., Gordon, L., and Escanez, J.: Decadal-scale chemical variability in the subtropical North Atlantic deduced from nutrient and oxygen data, J. Geophys. Res.-Ocean, 103, 2817-2830, 1998.

Garcia, H. E. and Gordon, L. I.: Oxygen solubility in water: better fitting equations, Limnology and Oceanography, 37, 1307-1312, 1992.

Gebbie, G. and Huybers, P.: Total Matrix Intercomparison: A Method for Determining the Geometry of Water-Mass Pathways, J. Phys. Oceanogr., 40, 1710-1728, doi:10.1175/2010jpo4272.1, 2010.

Hall, T. M., Waugh, D. W., Haine, T. W. N., Robbins, P. E., and Khatiwala, S.: Estimates of anthropogenic carbon in the Indian Ocean with allowance for mixing and time-varying airsea $\mathrm{CO}_{2}$ disequilibrium, Global Biogeochem. Cy., 18, Gb1031, doi:10.1029/2003gb002120, 2004.

Hansell, D. A. and Carlson, C. A.: Biogeochemistry of total organic carbon and nitrogen in the Sargasso Sea: control by convective overturn, Deep-Sea Res. Pt. II, 48, 1649-1667, 2001. 
Hansell, D. A., Bates, N. R., and Olson, D. B.: Excess nitrate and nitrogen fixation in the North Atlantic Ocean, Mar. Chem., 84, 243-265, 2004.

Jenkins, W. J.: Tritium-Helium dating in Sargasso Sea - measurement of oxygen utilization rates, Science, 196, 291-292, 1977.

Jenkins, W. J.: Tritium and He-3 in the Sargasso Sea, J. Mar. Res., 38, 533-569, 1980.

Jenkins, W. J.: The use of anthropogenic tritium and He-3 to study sub-tropical gyre ventilation and circulation, Philos. T. R. Soc. A, 325, 43-61, 1988.

Jenkins, W. J.: Studying subtropical thermocline ventilation and circulation using tritium and He-3, J. Geophys. Res.-Ocean, 103, 15817-15831, 1998.

Kadko, D.: Rapid oxygen utilization in the ocean twilight zone assessed with the cosmogenic isotope (7)Be (vol 23, GB4010, 2009), Global Biogeochem. Cy., 23, Gb4099, doi:10.1029/2009gb003706, 2009.

Keeling, C. D., Brix, H., and Gruber, N.: Seasonal and longterm dynamics of the upper ocean carbon cycle at Station ALOHA near Hawaii, Global Biogeochem. Cy., 18, doi:10.1029/2004GB002227, 2004.

Keeling, R. F., Kortzinger, A., and Gruber, N.: Ocean Deoxygenation in a Warming World, Annu. Rev. Mar. Sci., 2, 199-229, doi:10.1146/annurev.marine.010908.163855, 2010.

Khatiwala, S.: A computational framework for simulation of biogeochemical tracers in the ocean, Global Biogeochem. Cy., 21, Gb3001, doi:10.1029/2007gb002923, 2007.

Knap, A. H., Michaels, A. F., Steinberg, D. K., Bahr, F., Bates, N. R., Bell, S., Countway, P., Close, A. R., Doyle, A. P., Dow, R. L., Howse, F. A., Gundersen, K., Johnson, R. J., Kelly, R., Little, R., Orcutt, K., Parsons, R., Rathburn, C., Sanderson, M., and Stone, S.: BATS methods manual, Version 4, US JGOFS Planning Office, Woods Hole, MA, 1997.

Knapp, G. P.: Hydrographic data from the R.V. Endeavor cruise 129, in: WHOI (Series) - 88-41. Tehcnical report, Woods Hole Oceanographic Institution, Woods Hole, 1988.

Lam, P. J., Doney, S. C., and Bishop, J. K. B.: The dyanmic ocean biological pump: Insights from a global compilation of particulate organic carbon, $\mathrm{CaCO} 3$, and opal concentration profiles from the mesopelagic, Global Biogeochem. Cy., 25, doi:10.1029/2010GB003868, 2011.

Lee, C., Peterson, M. L., Wakeham, S. G., Armstrong, R. A., Cochran, J. K., Miquel, J. C., Fowler, S. W., Hirschberg, D., Beck, A., and Xue, J. H.: Particulate organic matter and ballast fluxes measured using time-series and settling velocity sediment traps in the northwestern Mediterranean Sea, Deep-Sea Res. Pt. II, 56, 1420-1436, doi:10.1016/j.dsr2.2008.11.029, 2009.

Locarnini, R. A., Mishonov, A. V., Antonov, J. I., Boyer, T. P., Garcia, H. E., Baranova, O. K., Zweng, M. M., and Johnson, D. R.: World Ocean Atlas 2009, Volume 1: Temperature, edited by: Levitus, S., U.S. Government Printing Office, Washington D.C., 184 pp., 2009.

Lomas, M. W., Steinberg, D. K., Dickey, T., Carlson, C. A., Nelson, N. B., Condon, R. H., and Bates, N. R.: Increased ocean carbon export in the Sargasso Sea linked to climate variability is countered by its enhanced mesopelagic attenuation, Biogeosciences, 7, 57-70, doi:10.5194/bg-7-57-2010, 2010.

Lott, D. E. and Jenkins, W. J.: Advances in analysis and shipboard processing of tritium and helium samples, International WOCE
Newsletter, 30, 27-30, 1998.

Lutz, M. J., Caldeira, K., Dunbar, R. B., and Behrenfeld, M. J.: Seasonal rhythms of net primary production and particulate organic carbon flux to depth describe the efficiency of biological pump in the global ocean, J. Geophys. Res.-Ocean, 112, C10011, doi:10.1029/2006jc003706, 2007.

MacMahon, D.: Half-life evaluations for H-3, Sr-90, and Y-90, Applied Radiation and Isotopes, 64, 1417-1419, 2006.

Maiti, K., Benitez-Nelson, C. R., and Buesseler, K. O.: Insights into particle formation and remineralization using the short-lived radionuclide, Thoruim-234, Geophys. Res. Lett., 37, L15608, doi:10.1029/2010g1044063, 2010.

Martin, J. H., Knauer, G. A., Karl, D. M., and Broenkow, W. W.: VERTEX: carbon cycling in the northeast Pacific, Deep-Sea Res., 34, 267-285., 1987.

Matear, R. J. and Hirst, A. C.: Long-term changes in dissolved oxygen concentrations in the ocean caused by protracted global warming, Global Biogeochem. Cy., 17, 2003.

Michaels, A. F., Bates, N. R., Buesseler, K. O., Carlson, C. A., and Knap, A. H.: Carbon system imbalances in the Sargasso Sea, Nature, 372, 537-540, 1994.

Michaels, A. F. and Knap, A. H.: Overview of the U.S. JGOFS Bermuda Atlantic Time-series Study and the Hydrostation S program, Deep-Sea Res. Pt. II, 43, 157-198, 1996.

Plattner, G. K., Joos, F., Stocker, T. F., and Marchal, O.: Feedback mechanisms and sensitivities of ocean carbon uptake under global warming, Tellus B, 53, 564-592, doi:10.1034/j.16000889.2001.530504.x, 2001.

Quay, P. and Stutsman, J.: Surface layer carbon budget for the subtropical N. Pacific: delta C-13 constraints at station ALOHA, Deep-Sea Res. Pt. I, 50, 1045-1061, 2003.

Robbins, P. E., Price, J. F., Owens, W. B., and Jenkins, W. J.: The importance of lateral diffusion for the ventilation of the lower thermocline in the subtropical North Atlantic, J. Phys. Oceanogr., 30, 67-89, doi:10.1175/15200485(2000)030<0067:tioldf $>2.0$. co;2, 2000.

Siegel, D. A. and Deuser, W. G.: Trajectories of sinking particles in the Sargasso Sea: modeling of statistical funnels above deep-ocean sediment traps, Deep-Sea Res. Pt. I, 44, 1519-1541, doi:10.1016/s0967-0637(97)00028-9, 1997.

Siegel, D. A., Fields, E., and Buesseler, K. O.: A bottomup view of the biological pump: Modeling source funnels above ocean sediment traps, Deep-Sea Res. Pt. I, 55, 108-127, doi:10.1016/j.dsr.2007.10.006, 2008.

Smethie, W. M. and Fine, R. A.: Rates of North Atlantic Deep Water formation calculated from chlorofluorocarbon inventories, DeepSea Res. Pt. I, 48, 189-215, doi:10.1016/s0967-0637(00)000480, 2001.

Spitzer, W. S. and Jenkins, W. J.: Rates of vertical mixing, gasexchange and new production - estimates from seasonal gas cycles in the upper ocean near Bermuda, J. Mar. Res., 47, 169-196, 1989.

Stanley, R. H. R., Buesseler, K. O., Manganini, S. J., Steinberg, D. K., and Valdes, J. R.: A comparison of major and minor elemental fluxes collected in neutrally buoyant and surface-tethered sediment traps, Deep-Sea Res. Pt. I, 51, 1387-1395, 2004.

Stanley, R. H. R., Baschek, B., Lott, D. E., and Jenkins, W. J.: A new automated method for measuring noble gases and their isotopic ratios in water samples, Geochem. Geophys. Geosyst., 10, 
doi:10.1029/2009GC002429, 2009.

Steinberg, D. K., Carlson, C. A., Bates, N. R., Johnson, R. J., Michaels, A. F., and Knap, A. H.: Overview of the US JGOFS Bermuda Atlantic Time-series Study (BATS): a decade-scale look at ocean biology and biogeochemistry, Deep-Sea Res. Pt. II, 48, 1405-1447, doi:10.1016/s0967-0645(00)00148-x, 2001.

Stommel, H.: Determination of water mass properties of water pumped down from the Ekman layer to the geostrophic flow below, Proceedings of the National Academy of Science, U.S.A., 76, 3051-3055, 1979.

Stramma, L., Johnson, G. C., Sprintall, J., and Mohrholz, V.: Expanding oxygen-minimum zones in the tropical oceans, Science, 320, 655-658, doi:10.1126/science.1153847, 2008.

Stramma, L., Schmidtko, S., Levin, L. A., and Johnson, G. C.: Ocean oxygen minima expansions and their biological impacts, Deep-Sea Research Pt. I, 57, 587-595, doi:10.1016/j.dsr.2010.01.005, 2010.

Talley, L. D.: Shallow, intermediate, and deep overturning components of the global heat budget, J. Phys. Oceanogr., 33, 530 560, doi:10.1175/1520-0485(2003)033<0530:siadoc $>2.0$. co;2, 2003.

Vaquer-Sunyer, R. and Duarte, C. M.: Thresholds of hypoxia for marine biodiversity, Proceedings of the National Academy of Sciences of the United States of America, 105, 15452-15457, doi:10.1073/pnas.0803833105, 2008.
Wallmann, K.: Feedbacks between oceanic redox states and marine productivity: A model perspective focused on benthic phosphorus cycling, Global Biogeochem. Cy., 17, 1084, doi:10.1029/2002gb001968, 2003.

Waugh, D. W., Hall, T. M., and Haine, T. W. N.: Relationships among tracer ages, J. Geophys. Res.-Ocean, 108, 3138, 2003.

Waugh, D. W., Haine, T. W. N., and Hall, T. M.: Transport times and anthropogenic carbon in the subpolar North Atlantic Ocean, Deep-Sea Res. Part I-Oceanogr. Res. Pap., 51, 14751491, doi:10.1016/j.dsr.2004.06.011, 2004.

Waugh, D. W., Hall, T. M., McNeil, B. I., Key, R., and Matear, R. J.: Anthropogenic $\mathrm{CO}(2)$ in the oceans estimated using transit time distributions, Tellus B, 58, 376-389, doi:10.1111/j.16000889.2006.00222.x, 2006.

Whitney, F. A., Freeland, H. J., and Robert, M.: Persistently declining oxygen levels in the interior waters of the eastern subarctic Pacific, Prog. Oceanogr., 75, 179-199, 2007.

Williams, R. G., Spall, M. A., and Marshall, J. C.: Does Stommel's mixed layer "demon" work?, J. Phys. Oceanogr., 25, 3089-3102, doi:10.1175/1520-0485(1995)025<3089:dsmlw>2.0.co;2, 1995. 